\title{
Video thumb mobility assessment
}

\section{Introduction}

Thumb mobility represents $40 \%$ to $50 \%$ of hand function. ${ }^{1,2}$ The thumb is able to make simultaneously or separately several movements, thus it can carry out the retropulsion, abduction, adduction, antepulsion, opposition, flexion, extension and the pronation-supination. The combination of these various movements led to circumduction which is a combined movement that starts with the maximum abduction retropulsion to antepulsion, continuing by the opposition and ending by the flexion.

Thus the trapezeus-metacarpal, metacarpophalangeal and interphalangeal joints give to thumb a large degree of mobility, with two degrees of freedom ${ }^{3-5}$ and a negligible rotation degree.,

The complexity of these movements makes it difficult to assess thumb mobility; that is why, several studies were carried out to evaluate thumb mobility and some assessed this mobility in only one plan, ${ }^{5,7}$ others assessed it in two plans ${ }^{4,8-11}$ and others assessed it in three plans, ${ }^{12,1,13}$ but no consensus has been used so far for the quantification of thumb mobility especially in clinical practice.

In this study, we suggest a method of thumb mobility assessment in only one plan, simple execution, within the reach of any surgeon in a consulting-room; this method is able to calculate the thumb circumduction surface, thus, including all combined movements of the thumb, giving an overall assessment of the thumb mobility.

\section{Materials and methods}

We assessed 30 participants ( 11 women and 19 men); we excluded all participants who had a thumb injury, a paralysis or after-effect of paralysis of one of the three nerves of the upper limb. The average age was 37 years ( $50-20$ years); we assessed the thumb mobility by asking the participants to make a full circumduction movement. We assessed the mobility of the two thumbs in order to compare the results.

Circumduction is a movement which starts by maximum abduction retropulsion of the thumb in the same plan as the palm of the hand, through the antepulsion where the thumb becomes perpendicular to the palm of the hand with a maximum metacarpophalangeal and interphalangeal extension and a maximum opening angle between the first and the second metacarpal, then the opposition which combines $15^{\circ}$ to $20^{\circ}$ of metacarpophalangeal flexion with a thumb pronation and finally the movement finishes by a flexion which combines a maximum flexion of metacarpophalangeal and interphalangeal, putting the pulp of the thumb in contact with the head of the fifth metacarpal.

Our method measures the surface of thumb circumduction in its maximum amplitude, for that we used a standard digital camera for the video and two software which are available in any hardware store. The first is vector graphic manipulation software called Adobe Macromedia Flash to plot the curve including the thumb movement, the second is computer-assisted design software called Autocad for the calculation of the surface.

\section{Procedure}

\section{Video footage captures}

Patient is placed in front of the camera; the slight shoulder adduction allows a maximum supination of the forearm, the elbow
Volume 10 Issue 2 - 2018

\author{
YacineTalbi, Neceri Yacine, Ouahmed Amer \\ Said Ait Messaoudène Military Hospital, University of Algiers, \\ Algeria
}

Correspondence: YacineTalbi, Said Ait Messaoudène Military Hospital, University of Algiers, Cité 445 Lgt, Bt 25, N I2, Sidi Menif. Zeralda, Algeria, Tel 00213560335069, Email talbiyacin6@gmail.com

Received: March 13, 2018| Published: April II, 2018

in a certain degree of flexion, the wrist and metacarpophalangeal joints are maintained by a splint with Velcro strips, avoiding all parasitic movement at the level of these two joints that can distort measurements. The splint should be thick enough to allow a maximum retropulsion of the thumb compared to the work plan (Figure 1). The camera is positioned on the same work plan as the patient's hand, in the axis of the third finger. A centimetric measurement support is positioned in the same plan as the tip of the thumb in order to be used as a measurement scale for later calculation of the surface. In this case the distance separating the camera with the patient's hand does not affect the result, since we have a fixed centimetric scale.

Then, you ask the patient to make the thumb circumduction movement, taking video footage from the beginning to the end of the movement.

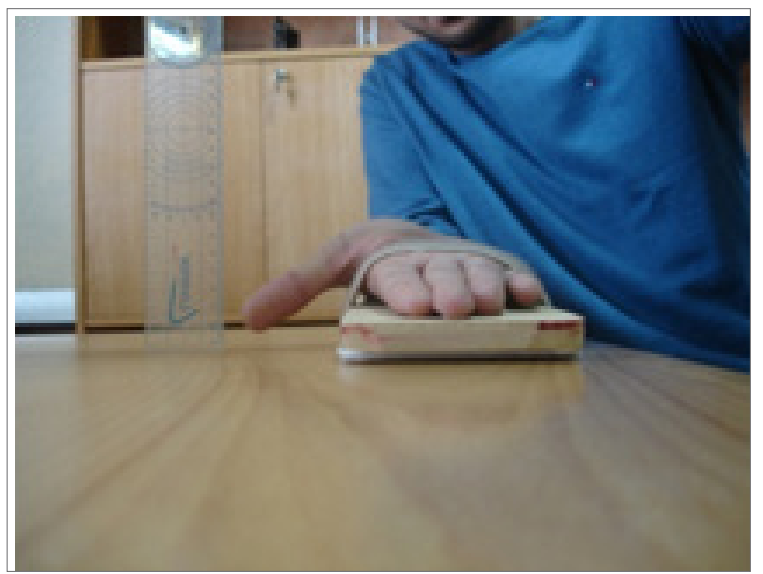

Figure I Video footage captures. Patient is front of the camera allows maximum supination and retropulsion of thumb.

\section{Movement contour tracing}

The video recording of the movement is transferred to Adobe Macromedia Flash, which marks a point on the tip of the thumb pulp every ten pictures from the beginning to the end of the movement, then, the points are connected to each other from of the first to the last closing the loop (Figure 2).

On the same video, you trace on the centimetric support the length of 01 centimetre, this one will serve as scale for the later calculation of surface; in this way, the calculation will be accurate with no risk of 
error since centimetric measurement is unchangeable. In this case, the distance which separates the camera from the hand will not affect the results of calculations since the scale is fixed $(01 \mathrm{~cm})$.

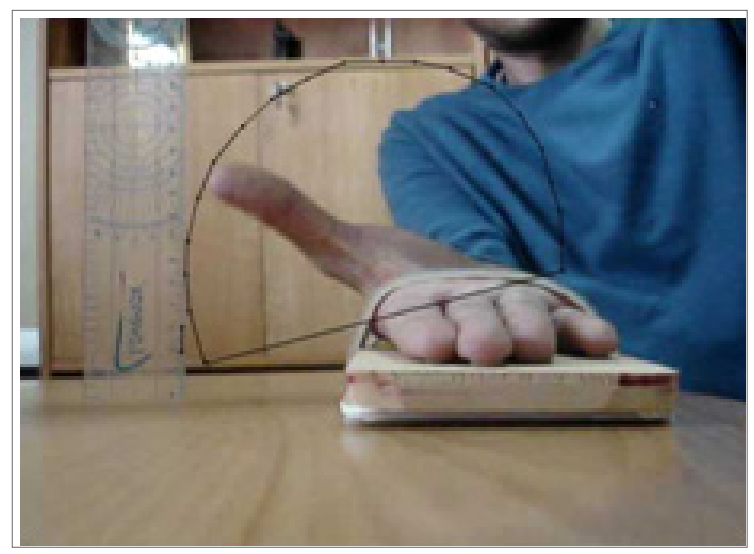

Figure 2 Movement contour tracing. Marks a point on the tip of the thumb pulp every ten pictures from the beginning to the end of the movement and we trace one centimetre on the centimetric support.

\section{Calculation of the area}

The movement contour tracing and the marking of centimetric measurement are then transferred on Autocad for the surface calculation (Figure 3). The measurement scale of will be the centimetre taken with the curve, on which Autocad is based for the calculation of the circumduction surface. Thus, you obtain a surface in square centimetre with a millimetre-length precision.

In our study, the two hands were assessed; we started with the dominant hand, then the controlateral hand in the same way.

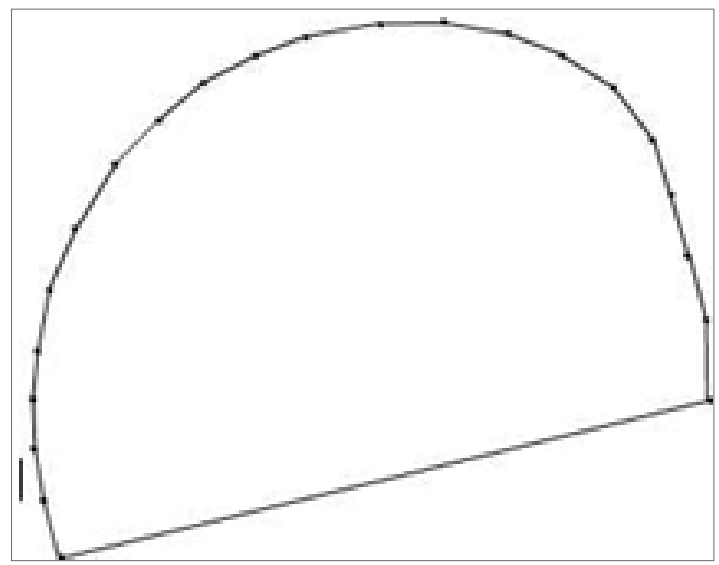

Figure 3 Calculation of the area.We transfer the measurement scale and the curve on Autocad for calculation of the surface.

\section{Results}

The obtained results on the dominant hand were compared with the controlateral hand. You noticed that the obtained surfaces between the two hands are almost identical; in this case, during the assessment of a pathological thumb the results will be compared with the healthy thumb to quantify the exact deficit of the thumb mobility (Table 1).
Consequently, you can assess the pathological thumb preoperatively then postoperatively to evaluate the mobility gain and compare results with the healthy side to assess residual postoperative deficit.

Table I Assessment of a pathological thumb the results will be compared with the healthy thumb to quantify the exact deficit of the thumb mobility

\begin{tabular}{|c|c|c|}
\hline & Left thumb & Right thumb \\
\hline Ist patient & $110,98 \mathrm{~cm}^{2}$ & $111,22 \mathrm{~cm}^{2}$ \\
\hline $2^{\text {nd }}$ patient & $138,1 \mathrm{I} \mathrm{cm}^{2}$ & $138,39 \mathrm{~cm}^{2}$ \\
\hline $3^{\text {th }} d$ patient & $63,84 \mathrm{~cm}^{2}$ & $64,12 \mathrm{~cm}^{2}$ \\
\hline $4^{\text {th }}$ patient & $137,21 \mathrm{~cm}^{2}$ & $137,30 \mathrm{~cm}^{2}$ \\
\hline $5^{\text {th }}$ patient & $82,56 \mathrm{~cm}^{2}$ & $82,78 \mathrm{~cm}^{2}$ \\
\hline $6^{\text {th }}$ patient & $96,78 \mathrm{~cm}^{2}$ & $96,91 \mathrm{~cm}^{2}$ \\
\hline $7^{\text {th }}$ patient & $108,63 \mathrm{~cm}^{2}$ & $108,88 \mathrm{~cm}^{2}$ \\
\hline $8^{\text {th }}$ patient & $95,88 \mathrm{~cm}^{2}$ & $96,00 \mathrm{~cm}^{2}$ \\
\hline $9^{\text {th }}$ patient & $126,46 \mathrm{~cm}^{2}$ & $126,52 \mathrm{~cm}^{2}$ \\
\hline $10^{\text {th }}$ patient & $138,58 \mathrm{~cm}^{2}$ & $138,43 \mathrm{~cm}^{2}$ \\
\hline I I ${ }^{\text {th }}$ patient & $104,66 \mathrm{~cm}^{2}$ & $104,78 \mathrm{~cm}^{2}$ \\
\hline $12^{\text {th }}$ patient & $122,03 \mathrm{~cm}^{2}$ & $121,87 \mathrm{~cm}^{2}$ \\
\hline $13^{\text {th }}$ patient & $113,08 \mathrm{~cm}^{2}$ & $113,21 \mathrm{~cm}^{2}$ \\
\hline $14^{\text {th }}$ patient & $99,41 \mathrm{~cm}^{2}$ & $99,60 \mathrm{~cm}^{2}$ \\
\hline $15^{\text {th }}$ patient & $128,00 \mathrm{~cm}^{2}$ & $128,05 \mathrm{~cm}^{2}$ \\
\hline $16^{\text {th }}$ patient & $130,23 \mathrm{~cm}^{2}$ & $130,34 \mathrm{~cm}^{2}$ \\
\hline $17^{\text {th }}$ patient & $\mathrm{I} / 4,80 \mathrm{~cm}^{2}$ & I $14,82 \mathrm{~cm}^{2}$ \\
\hline $18^{\text {th }}$ patient & $89,04 \mathrm{~cm}^{2}$ & $89,11 \mathrm{~cm}^{2}$ \\
\hline $19^{\text {th }}$ patient & $123,12 \mathrm{~cm}^{2}$ & $123,31 \mathrm{~cm}^{2}$ \\
\hline $20^{\text {th }}$ patient & $112,61 \mathrm{~cm}^{2}$ & $\mathrm{I} / 2,54 \mathrm{~cm}^{2}$ \\
\hline $2 I^{\text {th }}$ patient & $135,77 \mathrm{~cm}^{2}$ & $135,54 \mathrm{~cm}^{2}$ \\
\hline $22^{\text {th }}$ patient & $88,02 \mathrm{~cm}^{2}$ & $87,93 \mathrm{~cm}^{2}$ \\
\hline $23^{\text {th }}$ patient & $129,00 \mathrm{~cm}^{2}$ & $129,28 \mathrm{~cm}^{2}$ \\
\hline $24^{\text {th }}$ patient & $\mathrm{I} 10,84 \mathrm{~cm}^{2}$ & $\mathrm{I} 10,77 \mathrm{~cm}^{2}$ \\
\hline $25^{\text {th }}$ patient & $132,21 \mathrm{~cm}^{2}$ & $132,33 \mathrm{~cm}^{2}$ \\
\hline $26^{\text {th }}$ patient & $89,98 \mathrm{~cm}^{2}$ & $90,03 \mathrm{~cm}^{2}$ \\
\hline $27^{\text {th }}$ patient & $129,74 \mathrm{~cm}^{2}$ & $129,59 \mathrm{~cm}^{2}$ \\
\hline $28^{\text {th }}$ patient & $79,49 \mathrm{~cm}^{2}$ & $79,64 \mathrm{~cm}^{2}$ \\
\hline $29^{\text {th }}$ patient & $93,88 \mathrm{~cm}^{2}$ & $93,69 \mathrm{~cm}^{2}$ \\
\hline $30^{\text {th }}$ patient & $101,79 \mathrm{~cm}^{2}$ & $101,62 \mathrm{~cm}^{2}$ \\
\hline
\end{tabular}




\section{Discussion}

Most suggested methods to evaluate thumb mobility were carried out in laboratories with sophisticated material; ${ }^{12-14}$ we developed an easy evaluation method of thumb mobility, doable by any hand surgeon in consultation.

The obtained results did not show any difference between both hands, enabling the clinician to have a reference (healthy thumb) to use for the pre and post operative assessment of the pathological thumb. Using a centimetric support in the same plan that the thumb enables to have an unchangeable scale for the calculation of the surface; in this case, regardless the distance which separates the camera from the hand.The obtained results will be real and accurate.

The limitation of this method is the thumb mobility assessment in only one plan of space compared to other methods, ${ }^{12-14}$ but which seems sufficient for clinical practice since this method assesses the overall surface of circumduction, which gathers several thumb movements and which can be used by all hand surgeons in consultation.

The only risks of miscalculations are due to the fact that patients do not carry out the same mobility amplitudes during circumduction. Several methods assessed thumb rotation during circumduction, Sartorius used a goniometer for the calculation of thumb mobility amplitudes, ${ }^{7}$ Duparc et al. ${ }^{15}$ used metal pins on thumb and second finger and used an anthropostereometer to measure thumb circumduction. Jakobs \& Thompson ${ }^{10}$ suggested a classification to score thumb opposition, angle of the nail plan compared to palm of the hand.

Bunne ${ }^{16}$ used toothpicks attached on the thumb to show thumb rotation at $90^{\circ}$ during circumduction, Boys compared the angle thumbnail compared to the hand palm and tested the distance between the thumb pulp compared to the third finger. ${ }^{17}$ Cooney et al. ${ }^{4}$ attached markers on phalange and metacarpals of the thumb and third finger to study space relation between trapezius and the third finger.

Foucher used a special device to measure Van Wetter's Apogee and Duparc opposition angle circumduction was measured according to Kapandji quotation. ${ }^{18}$ Coert $^{13}$ described a technique to assess thumb rotation during the circumduction using a camera which emits an infra-red light and sensors attached on the thumb. Tang ${ }^{14}$ calculate thumb functional space during circumduction and concluded that the thumb moves to $60 \%$ of its total mobility in the abduction/adduction and flexion/extension during its functional mobility.

Zhang ${ }^{12}$ used 5 cameras, with markers placed on the thumb and long fingers and calculated the rotation centre and the thumb activity sphere in $3 \mathrm{~d}$. The trapezoid-metacarpal, metacarpophalangeal and interphalangeal joints are very complex, the thumb mobility is ensured by several intrinsic and extrinsic muscles, innervated by three different nerves. Each nerve injury can generate a different functional deficit of the thumb mobility. It seems that no method so far can assess in a comprehensive way this complex mobility of the thumb.

In most cases, these assessments are carried out in laboratories impossible to reproduce in consultation. The strength of our method is that it requires no specific material; it is simple to perform, reproducible, reliable and can be used for the assessment of any thumb pathology, whatever is paralytic, traumatic or osteoarthritis. ${ }^{19-21}$

\section{Acknowledgement}

None.

\section{Conflict of interest}

Authors declare there is no conflict of interest in publishing the article.

\section{References}

1. Swanson AB, Goran-Hagert C, Swanson GD. Evaluation of impairment in the upperextremity. Journal of Hand Surgery. 1987;12:896-925.

2. Ateshian GA, Ark JW, Rosenwasser MP, et al. Contact areas in the thumbcarpometacarpal joint. J Orthop Res. 1993;13(3):450-458.

3. Cooney WP, Chao EY. Biomecanicalanalysis of static forces in the thumbduring hand fuction. J Bone Joint Surg Am. 1977 ;59(1):27-36.

4. Cooney WP, Lucca MJ, Chao EYS, et al. The kinesiology of the thumbtrapeziometacarpal joint. J Bone Joint Surg Am. 1981;63(9):13711381 .

5. Kapandji IA. Biomechanic of the thumb. In: R Tubiana, editor. The hand. Philadelphia: WB Sanders; 1981:404-422.

6. Haines RW. The mechanism of rotation at the first carpometacarpal joint. J Ant. 1944;78(Pt 1-2):44-6.

7. Sartorius C. Principes pour une cotation fonctionnelle de la main. Annales chirurgie de la main 1987;6(1):51-57.

8. Eaton RG, Glickel SZ, Littler JW. Tendon interposition arthroplasty for degenerativearthritis of the trapeziometacarpal joint of the thumb. J Hand Surg Am. 1985;10(5):645-654.

9. Gilbert BG, Hahn HA, Gilmore WE et al. Tumbs up: Anthropometry of the first digit. Human Factors. 1988;30(6):747-750.

10. Jacobs B, Thompson TC. Opposition of the thumb and its rotation. Journal of bone and joint surgery. 1960;42:1015-1026.

11. Kuo I, Su F, Chiu H, et al. Feasibility of using a video-based motion analysis system for measuringthumbkinematic. J Biomech. 2002;35:499 1506.

12. Zhang. X, Braido P, Sang-Wook L. A normative database of thumb circumduction in vivo: center of rotation and range of motion. Human Factors. 2005;47(3):550-561.

13. Coert JH, van Dijke HG, Hovius SE et al. Quantifyingthumb rotation during circumduction utilizing a video technique. J Orthop Res. 2003;21(6):1151-1155.

14. Tang J, Zhang X, Zong-ming L. Operational and maximal workspace of thumb. Ergonomics. 2008;151(7):1109-1118.

15. Duparc J, de la Caffiniere JY, Pineau H. Approche biomecaniqueet cotation du premier metacarpien. Rev Chirurgie Orthop Reparatricel appareil Moteur 1971;57:3-12.

16. Bunnell S. Opposition of the thumb. J Bone Joint Surg 1938;20:269-85.

17. Boyes. Bunnell surgery of the hand. 3rd ed. Lipincott, 1964.

18. Duparc J, de la Caffiniere JY, Pineau H. Approche biomecaniqueet cotation du premier metacarpien. Rev Chirurgie Orthop Reparatricel appareil Moteur 1971;57:3-12.

19. Kapandji A. Cotation clinique de 1, opposition et de la contre opposition du pouce. Annales de la chirurgie de la main 1986, 5, 1,67-73.

20. Foucher G, Malizos C, Sammut D, et al. Primarypalmarislongustransfer as an opponensplasty in carpal tunnel release. J Hand Surg Br. 1991;16(1):5660 .

21. Cooney WP, Linscheid RL, An KN. Opposition of the thumb: An anatomic and biomechanicalstudy of tendon transfers. J Hand Surg Am 1984;9(6):777-86. 